ORIGINAL ARTICLE

\title{
Can a senior house officer's time be used more effectively?
}

\author{
J Mitchell, C Hayhurst, S M Robinson
}

Emerg Med J 2004;21:545-547. doi: 10.1136/emj.2003.007088

See end of article for authors' affiliations

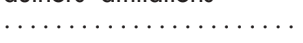

Correspondence to: Dr S M Robinson,

Addenbrookes N'H S Trust, Hills Road, Cambridge $\mathrm{CB} 1$ 6JD, UK. susan.robinson@ addenbrookes.nhs.uk

Accepted for publication 2 May 2003

\begin{abstract}
Objectives: To determine the amount of time senior house officers (SHO) spent performing tasks that could be delegated to a technician or administrative assistant and therefore to quantify the expected benefit that could be obtained by employing such physicians' assistants (PA).

Methods: SHOs working in the emergency department were observed for one week by pre-clinical students who had been trained to code and time each task performed by SHOs. Activity was grouped into four categories (clinical, technical, administrative, and other). Those activities in the technical and administrative categories were those we believed could be performed by a PA.

Results: The SHOs worked 430 hours in total, of which only 25 hours were not coded due to lack of an observer. Of the 405 hours observed $86.2 \%$ of time was accounted for by the various codes. The process of taking a history and examining patients accounted for an average of $22 \%$ of coded time. Writing the patient's notes accounted for an average of $20 \%$ of coded time. Discussion with relatives and patients accounted for $4.7 \%$ of coded time and performing procedures accounted for $5.2 \%$ of coded time. On average across all shifts, $15 \%$ of coded time was spent doing either technical or administrative tasks.

Conclusion: In this department an average of $15 \%$ of coded SHOs working time was spent performing administrative and technical tasks, rising to $17 \%$ of coded time during a night shift. This is equivalent to an average time of 78 minutes per 10 hour shift/SHO. Most tasks included in these categories could be performed by PAs thus potentially decreasing patient waiting times, improving risk management, allowing doctors to spend more time with their patients, and possibly improving doctors' training.
\end{abstract}

t has been recognised by both the Department of Health and doctors' representatives that doctors still perform nonmedical tasks unnecessarily. ${ }^{1-4}$ The role of nurses has been extended and there has been an increase in the availability of ward phlebotomists. Despite this, many doctors spend a significant proportion of their time performing uncomplicated and repetitive tasks that could be delegated to a trained assistant. Physicians have been shown to be spending less time with patients than before and that their "productivity" is declining. ${ }^{5}$

Extended waiting times in emergency departments (EDs) have been described as a failure of both access and quality. ${ }^{6}$ The effect of prolonged waiting times on patient morbidity and mortality in the UK has been the focus of much adverse publicity. The NHS plan has set the target that no patient should spend more than four hours in the ED. ${ }^{7}$ The number of patients attending EDs however continues to rise each year, patients have increasing expectations and staff within the ED are expected to do more for patients than was previously the case. The working hours of doctors in training have been decreased and are set to decrease still further. ${ }^{8}$ Principally doctors in training deliver the ED service in the UK, in such a climate it is imperative the time available for doctors to assess and treat patients is optimised.

The aim of this study was to determine the proportion of time spent by senior house officers (SHOs) performing tasks that could potentially be delegated to a technician and to quantify the expected benefit that could be obtained by employing physicians' assistants (PAs).

\section{METHODS}

In this study SHOs were observed throughout every shift for a week at the beginning of December 2001. Fifteen second year pre-clinical medical students were trained to code and time all activities performed by an SHO during a three hour teaching session. In addition they were briefed on confidentiality and professional working practices. A stopwatch was used to time each activity and times were then rounded up or down to the nearest 15 seconds.

The original codes were grouped into categories that represented clinical, technical, administrative, and other activities, for example, rest periods (see table 1). The activities in the administrative and technical categories were those that we believe could be performed safely by a technician or administrative assistant.

The study took place in the ED of an 823 bed university teaching hospital, which sees an average of 55500 new patient attendances per year. The departmental philosophy is to fully assess all patients and to develop management plans before patient discharge or referral. Ten SHOs, four specialist registrars, and 3.8 whole time equivalent consultants together with fixed clinical assistant sessions staff the department. At the time of the study the SHOs had completed two thirds of their post. SHO shifts are of 10 hours duration. In each 24 hour period there are two morning shifts, two middle day shifts, and two night shifts. Shifts were analysed altogether and subgroup analysis was performed comparing day shifts (0800-1800 and 0900-1900) with evening and night shifts (1900-0500 and 2200-0800). There was no overlap between shifts. Weekend shifts were also compared with weekday shifts.

Technical help is already available for 23 hours during weekday office hours. Our technician performs venesection, intravenous cannulation, and arterial blood gas sampling. In addition, $87 \%$ of the nursing staff are trained to perform intravenous cannulation and venesection.

\section{RESULTS}

During the seven day period of the study 956 patients attended the ED. A full complement of medical staff was present throughout and there was no reason to suspect abnormally low or high patient numbers during the study. The SHOs worked 430 hours in total, of which only 25 hours were not coded because of lack of an observer. Of the 
Table 1 Codes and average times for activities performed by emergency department SHOs across all shifts

\begin{tabular}{|c|c|c|c|c|}
\hline Category & Description of activity & $\begin{array}{l}\% \text { Of coded } \\
\text { time }\end{array}$ & $\begin{array}{l}\text { Average time } \\
\text { (h:min:s) }\end{array}$ & $\begin{array}{l}95 \% \text { Confidence } \\
\text { intervals (h:min:s) }\end{array}$ \\
\hline \multicolumn{5}{|l|}{ Clinical } \\
\hline CLIN & History, examination, assessment & 22.1 & $1: 54: 13$ & $1: 43: 11$ to $2: 05: 15$ \\
\hline TREA & Giving treatment & 1.5 & $0: 07: 48$ & $0: 03: 14$ to $0: 12: 22$ \\
\hline RELS & Explanation to relatives/patient & 4.7 & $0: 24: 09$ & $0: 19: 01$ to $0: 29: 17$ \\
\hline XRAY & Examining films & 2.2 & $0: 11: 36$ & $0: 09: 15$ to $0: 13: 57$ \\
\hline TRAUMA & All activities relating to major trauma & 0.9 & $0: 04: 48$ & $0: 00: 00$ to $0: 10: 35$ \\
\hline ARREST & All activities relating to arrest, post arrest & 1.0 & $0: 04: 55$ & $0: 00: 19$ to $0: 09: 31$ \\
\hline PROC & Performing procedure & 5.2 & $0: 26: 42$ & $0: 18: 40$ to $0: 34: 44$ \\
\hline DISC & Discussion with other specialties & 2.8 & $0: 14: 29$ & $0: 11: 01$ to $0: 17: 57$ \\
\hline DISC AE & Discussion with other ED staff & 5.4 & $0: 27: 44$ & $0: 21: 11$ to $0: 34: 17$ \\
\hline ADVICE & Giving telephone advice & 0.1 & $0: 00: 32$ & $0: 00: 01$ to $0: 01: 03$ \\
\hline NOTE & Writing notes & 20.0 & $1: 43: 16$ & $1: 33: 49$ to $1: 52: 43$ \\
\hline COD & Coding notes for data entry to produce GP letter & 3.5 & $0: 18: 02$ & $0: 15: 05$ to $0: 20: 59$ \\
\hline LEARN & Attending teaching or using reference books & 4.0 & $0: 20: 54$ & $0: 07: 54$ to $0: 33: 54$ \\
\hline TEACH & Teaching students & 1.0 & $0: 05: 16$ & $0: 01: 02$ to $0: 09: 30$ \\
\hline \multicolumn{5}{|l|}{ Technical } \\
\hline SEEK & Looking for equipment/nurses & 2.1 & $0: 10: 49$ & $0: 08: 25$ to $0: 13: 13$ \\
\hline PREP & Preparing for procedures & 1.5 & $0: 07: 46$ & $0: 05: 00$ to $0: 10: 32$ \\
\hline IV & Siting IV cannula & 0.6 & $0: 03: 18$ & $0: 00: 50$ to $0: 05: 46$ \\
\hline PHLEB & Taking blood & 0.7 & $0: 03: 40$ & $0: 02: 00$ to $0: 05: 20$ \\
\hline FORMS & Writing blood forms, sending samples & 1.4 & $0: 07: 23$ & $0: 05: 24$ to $0: 09: 22$ \\
\hline GAS & Taking blood gas measurements & 0.5 & $0: 02: 31$ & $0: 00: 52$ to $0: 04: 10$ \\
\hline $\begin{array}{l}\text { READY } \\
\text { Admin }\end{array}$ & Finding cubicle, calling and undressing patient & 3.3 & $0: 17: 05$ & $0: 10: 55$ to $0: 23: 15$ \\
\hline BLEEP & Bleeping other doctors - time taken to answer & 1.9 & $0: 09: 35$ & $0: 06: 42$ to $0: 12: 28$ \\
\hline TECH & Bleeping or talking to lab or radiographer & 2.4 & $0: 12: 37$ & $0: 09: 13$ to $0: 16: 01$ \\
\hline ANSPHO & Answering the phone (not after bleep) & 0.3 & $0: 01: 35$ & $0: 00: 55$ to $0: 02: 15$ \\
\hline \multicolumn{5}{|c|}{ 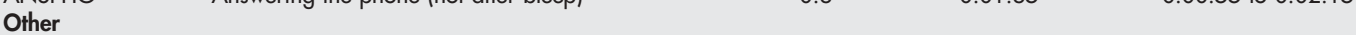 } \\
\hline EAT & Meal break & 4.7 & $0: 24: 09$ & $0: 20: 29$ to $0: 27: 49$ \\
\hline TEA & Making/drinking tea & 0.8 & $0: 03: 55$ & $0: 02: 05$ to $0: 05: 45$ \\
\hline BREAK & Any other sort of break & 3.0 & $0: 15: 29$ & $0: 09: 52$ to $0: 21: 06$ \\
\hline OTHER & Other activity - specified & 2.5 & $0: 12: 59$ & $0: 04: 12$ to $0: 21: 46$ \\
\hline
\end{tabular}

405 hours observed $86.2 \%$ of time was accounted for by the various codes.

The average time spent performing each task across all 10 hour shifts is shown in table 1 . The process of taking a history and examining patients accounted for an average of $22 \%$ of coded time. Writing the patient's notes accounted for an average of $20 \%$ of coded time. Discussion with relatives and patients accounted for $4.7 \%$ of coded time and performing procedures accounted for $5.2 \%$ of coded time.

The average time spent in discussion with other doctors accounted for $8.2 \%$ of coded time. Breaks accounted for $8.5 \%$ of coded time in total. This was less than the official time allotted per shift for breaks. Teaching medical students accounted for $1 \%$ of coded time.

On average across all shifts, 15\% of coded time was spent doing either technical or administrative tasks; technical tasks $10 \%$ ( $55 \mathrm{~min} 42 \mathrm{~s}, 95 \%$ CI $47 \mathrm{~min} 46 \mathrm{~s}$ to $63 \mathrm{~min} 38 \mathrm{~s}$ ); administrative tasks $5 \%$ (17 $\min 44 \mathrm{~s}, 95 \%$ CI $12 \min 52 \mathrm{~s}$ to $22 \min 36 \mathrm{~s}$ ).

During day shifts technical tasks accounted for an average of $9 \%$ of coded time ( $47 \mathrm{~min} 58 \mathrm{~s}, 95 \%$ CI $35 \mathrm{~min} 42 \mathrm{~s}$ to $60 \mathrm{~min} 13 \mathrm{~s})$ and administrative tasks $3 \%$ of coded time, ( $14 \mathrm{~min} 13 \mathrm{~s}, 95 \%$ CI $7 \mathrm{~min} 54 \mathrm{~s}$ to $20 \mathrm{~min} 32 \mathrm{~s}$ ). At night technical tasks rose to $12 \%$ of coded time (65 min 31 s, $95 \%$ $\mathrm{CI} 49 \mathrm{~min} 40 \mathrm{~s}$ to $1 \mathrm{~min} 23 \mathrm{~s}$ ). Administrative tasks accounted for $5 \%(25 \mathrm{~min} 45 \mathrm{~s}, 95 \%$ CI $15 \mathrm{~min} 6 \mathrm{~s}$ to 36 min 24 s) (see fig 1 ).

We found no statistically significant difference between the results obtained from weekend shifts when compared with weekday shifts.

\section{DISCUSSION}

To our knowledge this is the first time and motion study that looks specifically at ED SHOs. We demonstrated that an average of $12 \%$ of coded daytime was spent by SHOs performing administrative and technical tasks, rising to $17 \%$ of coded time during a night shift.

Use of PAs in the UK is uncommon, however a trained PA could perform many of the administrative and technical tasks currently performed by SHOs. Establishing such a post in our department would release on average 78 minutes per 10 hour shift/SHO. This would allow the doctors to spend more time per shift performing their primary role. In less well resourced departments, this effect is likely to be magnified. Indeed, pilot studies from two UK district general hospital EDs suggest that an average of $25 \%$ of doctors' time is spent performing uncomplicated administrative and technical tasks (J Mitchell, personal communication).

This study used direct real time observation by trained observers rather than other less reliable methods such as intermittent time sampling or self recording of tasks. We recognise there are limitations in using trained observers to
A

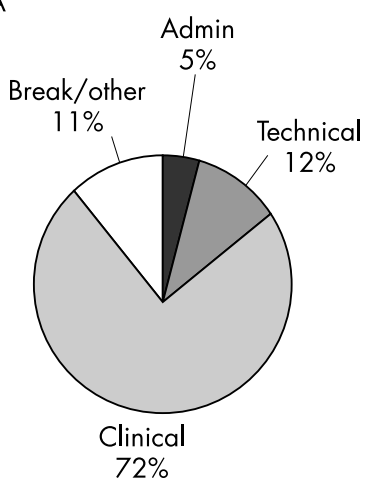

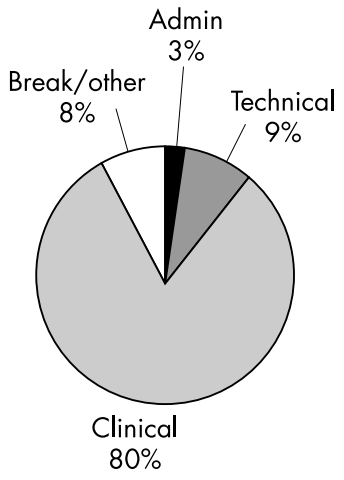

Figure 1 (A) SHO activity as a percentage of coded time-night shift. (B) SHO activity as a percentage of coded time-day shiff. 
observe in real time. The observers coded only $86.2 \%$ of time during the study. It is not clear whether non-coded time was mainly unproductive time or time spent doing tasks not identified by the observers. Observers noted that coding of activities was difficult when doctors were involved in multiple tasks. In this situation the observer timed the main activity. There is likely to be some observer effect leading to possible differences to usual working patterns as doctors were followed and closely observed. We hoped that by conducting the study over a whole week, the doctors might get used to the observer and perform their duties as usual.

There are some potentially significant advantages to reducing a doctor's administrative and technical workload. The most obvious is a doctor could see more patients per shift resulting in decreased waiting times. Decreasing patient waiting times in UK EDs is a high government priority. It has been shown that the proportion of patients that leave the ED without being seen is related to waiting time. ${ }^{9}$ Previous work has shown that such patients frequently have significant illness. $^{10}$

As an alternative to seeing more patients during a given shift, doctors could use the additional time generated by the presence of assistants to record better notes and to spend more time with each patient. Ideally a doctor's priority should be to provide high quality care rather than time limited care. Longer doctor-patient interactions favour patient centred care, which has also been shown to both improve patient outcomes and to reduce complaints in primary care. ${ }^{11}$ Further research is needed to fully assess the effect of these factors in the ED. Doctors may also have more time available per shift to supervise, teach and train their junior colleagues and medical students.

We believe that the widespread use of PAs has the potential to decrease patient waiting times, reduce the number of "did not wait events", improve risk management, and improve the quality of doctors training. These benefits would accrue without any increase in the number of doctors in post. More studies are needed to determine the effect of doctor's assistants in EDs on waiting times and "did not wait" events.

If PAs were to become established in the UK EDs as a new entity of healthcare worker, additional resources would be needed. The safety of patients is paramount and a recognised accredited training programme would be required. A two year training programme followed by two years on the job training has been suggested. ${ }^{3}$ A training programme in which healthcare assistants have been trained as "medical emergency assistants" and then work in the ED has been reported. ${ }^{12}$ In the UK, Castledine has previously cautioned against the introduction of doctor's assistants on the grounds that this would lead to competition over roles. ${ }^{13}$ We do not believe this would be a problem. PAs could relieve nurses of many non-nursing tasks such as patient transfer, stock control, and equipment checking; all of which are usually performed by nurses in the UK. ${ }^{14}$ A parallel study examining how much nursing time could be saved by being relieved of certain tasks might add weight to the case for creating PAs.

The process of recruitment of trainee PAs raises a number of concerns. The most common approach in the UK is for hospitals to employ nurses to help doctors perform venesection, intravenous cannulation, urinary catheterisation, and other similar tasks. It could be argued that nurses are needed to provide high quality nursing care and not to perform minor tasks previously done by doctors. There are problems both nationally and internationally with the recruitment and retention of skilled nurses so other potential sources of recruitment should be considered. Perhaps the most imaginative prospect however is the potential to attract new personnel to the healthcare workforce into this "new role".

In summary in our department an average of $15 \%$ of coded SHOs working time was spent performing administrative and technical tasks, rising to $17 \%$ of coded time during a night shift. Such tasks could be performed by PAs thus potentially decreasing patient waiting times, improving risk management, allowing doctors to spend more time with their patients, and possibly improving doctors' training, without any increase in the number of doctors in post.

\section{ACKNOWLEDGEMENTS}

The authors thank all the ED SHOs who participated in the study and the second year pre-clinical students of Cambridge University who acted as observers. We thank Ms K Mahon of Addenbrooke's Department of Clinical Audit and Effectiveness for her help in data entry and for the initial data analysis. We are grateful to The Leys School, Cambridge for the provision of stopwatches.

\section{Contributors}

JM conceived the original idea for the study and participated in its design. $\mathrm{CH}$ was involved in the design of the study, organised the staff and equipment required for the week of observation and trained the observers. CH analysed the data. SR was involved in the design of the study. All three authors participated in the writing of the paper. $\mathrm{CH}$ acts as guarantor for the paper.

\section{Authors' affiliations}

J Mitchell, East Anglian Rotation, UK

C Hayhurst, WEC International, Brikama, the Gambia

S M Robinson, Addenbrookes NHS Trust, Cambridge, UK

\section{REFERENCES}

1 Alberti G. We need a new breed-the medical assistant. Daily Telegraph 2000;20 Jan.

2 Hargadon J, Staniforth M. A health service of all the talents: developing the NHS workforce. London: Department of Health, 2000.

3 Hall C. New breed of medic to remove old barriers. Daily Telegraph 2000;7 Apr.

4 Orme M, Bloom S. Hospital doctors under pressure: new roles for healthcare workforce. London: Royal College of Physicians, 1999.

5 Rohme K, Kjekshus L. When time counts-hospital physicians use of time and work assignments. Tidssk Nor Laegeforan 2001;121:1458-61.

6 ACEM Policy Document. National triage scale. Emerg Med 1994;6:145-6.

7 Department of Health. The NHS plan. London: The Stationery Office, 2000.

8 Department of Health. Working time regulation-implementation in the NHS. HSC 1998/204.

9 Fernandes C, Price A, Christenson J. Does reduced length of stay decrease the number of emergency department patients who leave without seeing a physician? J Emerg Med 1997; 15:397-9.

10 Baker D, Stephens C, et al. Patients who leave a public hospital emergency department without being seen by a physician. JAMA 1991;266:1085-90.

11 Venning $P$, Durie $A$, Roland $M$, et al. Randomised controlled trial comparing cost effectiveness of general practitioners and nurse practitioners in primary care. BMJ 2000;320:1048-53.

12 Davison A, White V, China J, et al. Medical emergency assistants-helping with the hours and work intensity of junior hospital doctors. J R Coll Physicians Lond 2000;34:503.

13 Castledine G. Do we need physicians assistants in the UK? British Journal of Nursing 1996;5:124.

14 Hassell I. Working smarter, not harder-improving emergency department nurse productivity. Emergency Nurse 2001;8:7-8. 